\title{
PENENTUAN PENGARUH PEMANASAN DAN WAKTU PENYIMPANAN GARAM BERIODIUM TERHADAP KALIUM IODAT
}

\author{
Hena Sugiani ${ }^{\mathrm{a}}$, Popy Previanti ${ }^{\mathrm{a}}$, Sukrido $^{\mathrm{a}^{*}}, \&$ Uji Pratomo $^{\mathrm{b}}$ \\ ${ }^{a}$ Jurusan Kimia, Universitas Ahmad Yani \\ Jl. Terusan Jendral Sudirman, PO Box 148 Cimahi, Jawa Barat, Indonesia \\ ${ }^{\mathrm{b}}$ Departemen Kimia, Fakultas Matematika dan Ilmu Pengetahuan Alam, Universitas Padjadjaran \\ Jl. Raya Bandung-Sumedang km. 21 Jatinangor, Sumedang 45363, Jawa Barat - Indonesia \\ *Alamat korespondensi: sukrido_unjani@yahoo.com
}

\begin{abstract}
Abstrak: Iodium merupakan mineral yang diperlukan oleh tubuh dalam jumlah yang relatif sangat kecil, tetapi mempunyai peranan yang sangat penting untuk pembentukan hormon tiroksin. Iodium selain dapat diperoleh dari garam beriodium, juga dapat diperoleh dari air minum, sayuran dan bahan makanan dari laut. Tujuan penelitian ini adalah untuk mengetahui kadar air dalam garam beriodium yang telah beredar dipasaran, untuk mengetahui identifikasi ion-ion mineral yang terdapat dalam garam yang telah direkristalisasi dengan penambahan bahan pengikat, dan untuk mengetahui pengaruh penyimpanan dan pemanasan terhadap kadar iodium dalam garam beriodium. Hasil penelitian kadar iodium diperoleh dari minggu pertama sebesar 62,86 ppm, minggu kedua sebesar 60,95 ppm dan minggu ketiga sebesar 57,17 ppm. Kadar $\mathrm{KIO}_{3}$ dalam garam beriodium menunjukkan bahwa pada setiap minggunya kadarnya lebih tinggi dalam suhu ruang dibandingkan dengan yang sesudah dipanaskan. Sedangkan pada analisis ion mineral yang diukur dengan SSA menunjukkan bahwa konsentrasi $\mathrm{Ca}^{2+}$ dan $\mathrm{Mg}^{2+}$ di setiap minggunya lebih tinggi pada suhu ruang daripada setelah melalui pemanasan.
\end{abstract}

Kata kunci: Garam Berodium, Iodium (IO3), Spektrofotometri

\section{PENDAHULUAN}

Penanggulangan masalah GAKI (Gangguan Akibat Kekurangan Iodium) akan lebih efektif dan efisien apabila disertai pula dengan upaya untuk menghasilkan produk garam konsumsi beriodium yang bermutu sesuai dengan persyaratan Standar Nasional Indonesia oleh para pengusaha industri garam. Sesuai SNI nomor 01-3556-2000, garam beriodium adalah garam konsumsi yang mengandung komponen utama natrium klorida 94,7\%, air maksimal 5\% dan kalium iodat mineral 30 ppm, serta senyawa-senyawa lain sesuai persyaratan yang ditentukan. Iodium selain dapat diperoleh dari garam beriodium, juga dapat diperoleh dari air minum, sayuran dan bahan makanan dari laut. Kandungan iodium dalam air minum sangat tergantung pada kadar iodium dalam tanah tempat sumber air tersebut, dimana untuk daerah pegunungan kandungan iodium dalam air sangat sedikit dibanding di daerah pantai yang dekat dengan laut. Dalam sayur-sayuran kandungan iodiumnya tergantung pada keadaan tanah, pupuk dan lingkungan tempat sayuran tersebut diproduksi serta lamanya penyimpanan dan pemanasan karena iodium tidak tahan terhadap suhu tinggi.

Menurut keputusan Presiden No. 69 tahun 1994, semua garam yang beredar di Indonesia harus mengandung iodium yaitu garam yang telah diperkaya dengan kalium iodat $\left(\mathrm{KIO}_{3}\right)$. Hampir seluruh makanan menggunakan garam sebagai penyedap rasa, serta banyak digunakan untuk bahan tambahan dalam industri pangan, selain itu, karena harga garam dapur relatif murah dan terjangkau oleh semua lapisan masyarakat maka pemerintah memilih garam dapur menjadi garam konsumsi sebagai media penyampaian iodium ke dalam tubuh.

Proses pengeringan yang tidak sempurna menyebabkan mutu garam beriodium kurang baik sehingga menyebabkan penurunan kadar iodium selama penyimpanan. Penyimpanan garam di tempat terbuka dan terpapar sinar matahari sebaiknya dihindari. Adanya oksigen dan sinar matahari menyebabkan iodium mudah teroksidasi, sehingga berkurang jumlahnya karena kalium iodat dapat mengoksidasi zat-zat organik misalnya asam oksalat, dan zat anorganik misalnya garam ferro menjadi garam ferri dengan menghasilkan $I_{2}$. Garam beriodium sebaiknya disimpan di tempat yang tertutup dan gelap (Soengkawati \& Marihati, 2001).

\section{BAHAN DAN METODE}

Bahan yang digunakan dalam penelitian ini adalah $\mathrm{AgNO}_{3}$ 99,8 \%, aquadest, garam beriodium, $\mathrm{HCl}$ pekat $37 \%, \mathrm{HNO}_{3}$ pekat $65 \%, \mathrm{H}_{2} \mathrm{SO}_{4} 98 \%$, kertas indikator universal, $\mathrm{KI} 99,5 \%, \mathrm{KIO}_{3} 99,7 \%, \mathrm{NaOH}$ $99 \%,\left(\mathrm{NH}_{4}\right)_{2} \mathrm{CO}_{3} 99,5 \%$. Sedangkan metode yang digunakan dalam penelitian ini dilakukan dengan metode Spektrofotometri UV-Vis dan Spektrofotometri Serapan Atom.

\section{HASIL DAN PEMBAHASAN \\ Identifikasi Ion Garam}

Identifikasi garam beriodium dilakukan secara kualitatif dan kuantitatif. Penentuan kandungan mineral dalam garam beriodium sangat bermanfaat untuk mengetahui layak atau tidaknya garam 
beriodium itu dikonsumsi dan untuk mengetahui besarnya kenaikan ion mineral dan kadar air dalam garam beriodium yang dimurnikan melalui metode rekristalisasi. Hasil penelitian tentang identifikasi garam beriodium disajikan dalam tabel 1 .

Tabel 1. Identifikasi Sampel Garam Beriodium

\begin{tabular}{cc}
\hline Parameter Uji & Hasil Analisis \\
\hline $\mathrm{Ca}^{2+}$ & Positif \\
$\mathrm{Mg}^{2+}$ & Positif \\
Kadar Air & $0,1-7,8 \%$ \\
\hline
\end{tabular}

Identifikasi awal secara kualitatif pada $\mathrm{Ca}^{2+}$ dilakukan dengan penambahan $\mathrm{H}_{2} \mathrm{SO}_{4}$. Penambahan $\mathrm{H}_{2} \mathrm{SO}_{4}$ dimaksudkan untuk mengendapkan $\mathrm{Ca}^{2+}$ sebagai $\mathrm{CaSO}_{4}$.

$\mathrm{Ca}^{2+}{ }_{(\mathrm{aq})}+\mathrm{H}_{2} \mathrm{SO}_{4(\mathrm{aq})} \longrightarrow \mathrm{CaSO}_{4(\mathrm{~s})}+2 \mathrm{H}^{+}{ }_{(\mathrm{aq})}$

Identifikasi awal secara kualitatif pada ion $\mathrm{Mg}^{2+}$ dilakukan dengan penambahan $\mathrm{NaOH}$ dimaksudkan untuk mengendapkan $\mathrm{Mg}^{2+}$ sebagai $\mathrm{Mg}(\mathrm{OH})_{2}$.

$\mathrm{Mg}^{2+}{ }_{(\mathrm{aq})}+2 \mathrm{NaOH}_{(\mathrm{aq})} \longrightarrow \mathrm{Mg}(\mathrm{OH})_{2(\mathrm{~s})}+2 \mathrm{Na}^{+}{ }_{(\mathrm{aq})}$ Cek jumlah muatan kiri dan kanan

(Vogel, 1979).

Identifikasi akhir secara kuantitatif pada $\mathrm{Ca}^{2+}$ dan $\mathrm{Mg}^{2+}$ dilakukan dengan melarutkan garam beriodium dengan aquadest ke dalam tabung reaksi kemudian diukur dengan metode spektrofotometri serapan atom. Uji ini dilakukan sebelum proses rekristalisasi, tujuannya untuk mengetahui konsentrasi $\mathrm{Ca}^{2+}$ dan $\mathrm{Mg}^{2+}$ sebelumnya. Kemudian dihitung konsentrasi $\mathrm{Ca}^{2+}$ dalam larutan garam di dalam tabung reaksi dengan rumus yang sudah ditentukan, setelah dihitung maka didapatkan konsentrasi $\mathrm{Ca}^{2+}$ sebelum direkristalisasi sebesar 1,042 ppm. Sedangkan konsentrasi $\mathrm{Mg}^{2+}$ didapatkan sebesar 0,047 ppm.

\section{Rekristalisasi}

Proses pemurnian garam beriodium bertujuan untuk menghilangkan pengotor yang mungkin bercampur dengan garam, baik yang larut maupun yang tidak larut dalam air, agar kadar iodium dan konsentrasi $\mathrm{Ca}^{2+}$ dan $\mathrm{Mg}^{2+}$ dalam garam memenuhi syarat mutu garam konsumsi. Untuk memisahkan pengotor yang tidak larut dalam air dapat dilakukan dengan penyaringan menggunakan kertas saring. Adapun ion yang masih larut merupakan ion mineral di dalam garam yang masih bermanfaat untuk tubuh manusia, seperti $\mathrm{Ca}^{2+}$ dan $\mathrm{Mg}^{2+}$. Konsentrasi $\mathrm{Ca}^{2+}$ dan $\mathrm{Mg}^{2+}$ dihitung sebelum dan sesudah rekristalisasi.

\section{Kadar Air}

Dalam penelitian ini, rata - rata kadar air garam beriodium yang diperoleh dengan metode pengeringan oven berkisar $0,1-7,8 \%$. Namun setelah melalui proses rekristalisasi kadar airnya mengecil dibandingkan sebelum di rekristalisasi. Kadar air tersebut hampir mendekti batas maksimal yang diijinkan oleh SNI tentang mutu garam adalah untuk garam maksimal sebesar $7 \%$. Dari hasil penelitian ini, didapatkan rata - rata kadar yang berbeda-beda dalam setiap minggunya yang disajikan dalam tabel 2 berikut ini.

Tabel 2. Rata - Rata Kadar Air Setiap Minggu.

\begin{tabular}{ccc}
\hline $\begin{array}{c}\text { Minggu } \\
\text { Ke }\end{array}$ & $\begin{array}{c}\text { Sebelum Di } \\
\text { Rekristalisasi }\end{array}$ & $\begin{array}{c}\text { Sesudah Di } \\
\text { Rekristalisasi }\end{array}$ \\
\hline I & $0,1232 \%$ & $6,3426 \%$ \\
II & $1,8161 \%$ & $7,1639 \%$ \\
III & $3,7124 \%$ & $7,8400 \%$ \\
\hline
\end{tabular}

\section{Penentuan Panjang Gelombang Maksimum}

Warna yang dipantulkan oleh larutan $\mathrm{KIO}_{3}$ termasuk berada dalam spektrum sinar tampak atau visible, karenanya penentuan panjang gelombang larutan $\mathrm{KIO}_{3}$ dapat menggunakan spektrofotometer UV-Vis. Spektrofotometer UV-Vis adalah spektrofotometer yang mempunyai panjang gelombang 200-800 nm. Pada tabel hasil penelitian ini, diperoleh absorbansi maksimum pada panjang gelombang $350 \mathrm{~nm}$.

\section{Kurva Kalibrasi Larutan Standar $\mathrm{KIO}_{3}$}

Pada pengukuran terhadap larutan standar $\mathrm{KIO}_{3}$ yang dibuat dengan variasi konsentrasi 2, 4, 6, 8, 10 ppm diperoleh data kurva kalibrasi gambar 3 berikut ini.

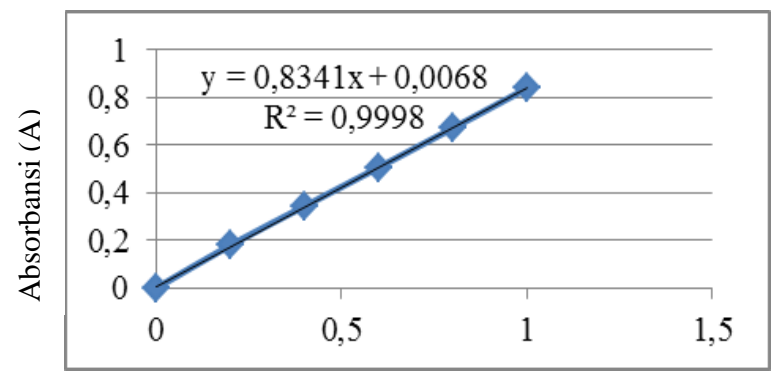

Konsentrasi (ppm)

Gambar 1. Penentuan Kurva Kalibrasi Larutan $\mathrm{KIO}_{3}$

\section{Kadar $\mathrm{KIO}_{3}$}

Proses penentuan konsentrasi dan kadar $\mathrm{KIO}_{3}$ menggunakan spektrofotometri UV-Vis dan diperoleh absorbansinya. Dari harga absorbansi, dapat dicari konsentrasi $\mathrm{KIO}_{3}$ dalam sampel dengan menggunakan persamaan regresi linear yang diperoleh dari persamaan kurva kalibrasi larutan standar $\mathrm{KIO}_{3}$. 
Tabel 3. Hasil kadar $\mathrm{KIO}_{3}$ dalam garam beriodium

\begin{tabular}{ccccc}
\hline \multirow{2}{*}{ Minggu Ke } & \multicolumn{4}{c}{ Kadar $_{\mathrm{KIO}_{\mathbf{3}}(\mathbf{m g})}$} \\
\cline { 2 - 5 } & $\mathbf{2 7}^{\mathbf{0}} \mathbf{C}$ & $\mathbf{3 0}^{\mathbf{0}} \mathbf{C}$ & $\mathbf{5 0}^{\mathbf{0}} \mathbf{C}$ & $\mathbf{1 0 0}^{\mathbf{0}} \mathbf{C}$ \\
\hline I & 63,6 & 63,05 & 62,6 & 62,2 \\
II & 61,8 & 61,35 & 60,8 & 59,85 \\
III & 57,8 & 57,65 & 57,25 & 56 \\
\hline
\end{tabular}

Berkurangnya kadar iodium disebabkan ada iodium yang hilang akibat lamanya garam tersebut beredar di pasaran dan proses pemanasan garam beriodium saat pengolahan (proses pemanasan pada saat memasak). Proses pemanasan akan mengurangi kestabilan $\mathrm{KIO}_{3}$ dalam garam dimana pada proses pemanasan $\mathrm{KIO}_{3}$ akan menjadi KI dengan reaksi sebagai berikut:

$2 \mathrm{KIO}_{3} \longrightarrow 2 \mathrm{KI}+3 \mathrm{O}_{2}$

(Soengkawati \& Marihati, 2001).

\section{Identifikasi Kuantitatif Ion Garam}

Pada identifikasi kuantitatif ion garam ini, penelitian dilakukan dengan menggunakan metode spektrofotometri serapan atom. Hasilnya dapat dilihat pada table 4 dan 5 .

Tabel 4. Hasil Analsisis Ion Ca Setelah Di Rekristalisasi Dengan metode SSA.

\begin{tabular}{ccccc}
\hline \multirow{2}{*}{ Minggu Ke } & \multicolumn{5}{c}{ Konsentrasi Ca (ppm) } \\
\cline { 2 - 5 } & $\mathbf{2 7}^{\mathbf{0}} \mathbf{C}$ & $\mathbf{3 0}^{\mathbf{0}} \mathbf{C}$ & $\mathbf{5 0}^{\mathbf{0}} \mathbf{C}$ & $\mathbf{1 0 0}^{\mathbf{}} \mathbf{C}$ \\
\hline I & 110,58 & 109,57 & 106,29 & 105,08 \\
II & 61,2 & 239,06 & 36,04 & 32,47 \\
III & 37,17 & 13,5 & 4,78 & 1,95 \\
\hline
\end{tabular}

Tabel 5. Hasil Analsisis Ion Mg Setelah Di Rekristalisasi Dengan metode SSA.

\begin{tabular}{ccccc}
\hline & \multicolumn{4}{c}{ Konsentrasi $\mathbf{M g}(\mathbf{p p m})$} \\
\cline { 2 - 5 } Minggu Ke & $\mathbf{2 7}^{\mathbf{0}} \mathbf{C}$ & $\mathbf{3 0}^{\mathbf{}} \mathbf{C}$ & $\mathbf{5 0}^{\mathbf{0}} \mathbf{C}$ & $\mathbf{1 0 0}^{\mathbf{C}} \mathbf{C}$ \\
\hline I & 3,1092 & 2,6538 & 2,2632 & 2,0872 \\
II & 2,0872 & 2,0123 & 1,9585 & 1,7535 \\
III & 0,71 & 0,45 & 0,31 & 0,12 \\
\hline
\end{tabular}

Dalam penelitian ini terlihat bahwa semakin lama waktu penyimpanannya maka akan semakin kecil konsentrasi yang terdapat dalam garam beriodium tersebut. Faktor yang mempengaruhi berkurangnya konsentrasi mineral tersebut disebabkan karena garam beriodium tidak tahan oleh suhu yang terlalu panas, udara terbuka, dan garam sangat mudah menguap serta mudah terkontaminasi jika terpapar sinar matahari. Adapun pencegahannya agar terhindar dari faktor-faktor tersebut ialah dengan menghindari paparan langsung sinar matahari, garam disimpan rapat dengan wadah yang tertutup di suhu ruang yang jauh dari sinar matahari, tidak menyimpan garam terlalu lama misalnya berbulanbulan, serta hindari memakai garam dengan suhu yang sangat panas ketika memasak karena dapat menurunkan konsentrasi dan kadar iodium dari $\mathrm{KIO}_{3}$ serta kandungan penting lainnya yang terkandung didalamnya.

\section{KESIMPULAN}

1. Pengaruh waktu penyimpanan terhadap kadar iodium dalam garam beriodium yaitu dapat menurunkan kualitas garam yang telah di produksi sebelumnya, maka dari itu sebaiknya hindari penyimpanan garam lebih dari 2 minggu karena iodium dapat berkurang secara signifikan.

2. Pengaruh pemanasan dalam garam beriodium dapat membuat garam kehilangan kadar iodium jika dipanaskan pada suhu tinggi $\left(>100{ }^{\circ} \mathrm{C}\right)$, karena dapat menurunkan konsentrasi iodium yang sudah sesuai dengan syarat standar mutu.

3. Terdapat kandungan air di dalam garam beriodium, maka dari itu perlu adanya pengeringan dengan metode oven, yang bertujuan untuk menghilangkan air tersebut.

4. Masih terdapat ion-ion mineral setelah direkristalisasi karena adanya bantuan penambahan senyawa impurities saat rekristalisasi untuk mengikat pengotor.

\section{DAFTAR PUSTAKA}

Almatsier, S. (2005). Identifikasi dan Penetapan Kalium Iodat dalam Garam Dapur yang Beredar di Pasar Kota Bitung dengan Metode Spektrofotometri UV-Vis. Pharmacon. Vol. 2 No. 01.

BPPI. (1984). Standarisasi Iodat dalam Garam Konsumsi. BPPI. Semarang.

Chairil, A. (1994). Pengantar Praktikum Kimia Organik. Fakultas Matematika dan Ilmu Pengetahuan Alam UGM. Yogyakarta.

Departemen Perindustrian. (1987). Standar Industri Indonesia (SII) No. 140. 1976. Syarat Mutu Barang. Departemen Perindustrian. Jakarta.

Djoko, W. (1995). Peningkatan Teknologi Proses Pengolahan Garam Rakyat Menjadi Garam Industri Dengan Tenaga Surya. Departemen Perindustrian RI BPPI. Semarang.

Kartasapoetra, G. (1995). Analisis Kandungan Iodium dalam Garam Butiran Konsumsi yang Beredar di Pasaran Kota Ambon. Biologi. Vol. 6 No. 2.

Kurnia, A. (1977). Sitematika Unsur-Unsur. Bintang Pelajar. Jakarta.

Muchtadi, D. (1993). Metabolisme Zat Dan Gizi Jilid II. Pustaka Sinar Harapan. Jakarta. 
Mujiran. (1982). Kimia Kuantitatif Anorganik. Univesitas Gajah Mada. Yogyakarta.

Mursandi, S. (1985). Garam Iodium Untuk Menanggulangi Penyakit Gondok Endemik Dan Kerdil Endemik. BPPI. Semarang.

Nadesul, H. (2000). Makanan Sehat Untuk Ibu Hamil. Puspaswara. Bandung.

Partono. (2001). Proses Penguapan air laut dan Prinsip Dasar Pembuatan Garam dari Air Laut. Dinas Perindustrian Jawa Timur. Pacitan.

Soengkawati, A. M. \& Marihati. (2001). Penelitian Kandungan Iodium Dalam Garam Konsumsi
Beriodium Di Tingkat Produsen Di Jawa Tengah Dan Faktor-Faktor Yang Berpengaruh Terhadap Kandungan Iodium Dalam Produk Akhir. Buletin Penelitian Dan Pengembangan Industri. 28.

Suharsimi A. (1993). Prosedur Penelitian. Bina Aksara. Jakarta.

Vogel. A. I., (1979). Text Of Macro And Semimicro Qualiltative Inorganic Analisys. Longman Group Limited. London. 